OPEN ACCESS

Edited by:

Amy Rasley,

Lawrence Livermore National

Laboratory (DOE), USA

Reviewed by:

Vladimir L. Motin,

University of Texas Medical Branch,

USA

M. Nadeem Khan,

Rochester General Hospital, USA

*Correspondence:

Shailendra Kumar Verma vermask@drde.drdo.in,

skvdrde@yahoo.co.in

Specialty section:

This article was submitted to

Microbial Immunology,

a section of the journal

Frontiers in Immunology

Received: 06 September 2016 Accepted: 30 November 2016

Published: 14 December 2016

Citation:

Verma SK and Tuteja U (2016) Plague Vaccine Development: Current Research and Future Trends. Front. Immunol. 7:602. doi: 10.3389/fimmu.2016.00602

\section{Plague Vaccine Development: Current Research and Future Trends}

\author{
Shailendra Kumar Verma* and Urmil Tuteja \\ Microbiology Division, Defence Research \& Development Establishment, Gwalior, India
}

Plague is one of the world's most lethal human diseases caused by Yersinia pestis, a Gram-negative bacterium. Despite overwhelming studies for many years worldwide, there is no safe and effective vaccine against this fatal disease. Inhalation of $Y$. pestis bacilli causes pneumonic plague, a fast growing and deadly dangerous disease. F1/ LcrV-based vaccines failed to provide adequate protection in African green monkey model in spite of providing protection in mice and cynomolgus macaques. There is still no explanation for this inconsistent efficacy, and scientists leg behind to search reliable correlate assays for immune protection. These paucities are the main barriers to improve the effectiveness of plague vaccine. In the present scenario, one has to pay special attention to elicit strong cellular immune response in developing a next-generation vaccine against plague. Here, we review the scientific contributions and existing progress in developing subunit vaccines, the role of molecular adjuvants; DNA vaccines; live delivery platforms; and attenuated vaccines developed to counteract virulent strains of $Y$. pestis.

Keywords: plague, Yersinia pestis, molecular adjuvants, subunit vaccines, lethal disease, cellular immunity, DNA vaccines, live delivery

\section{INTRODUCTION}

Plague is a historic disaster which has caused 200 millions of deaths during the pandemics (1). It is an enzootic disease and prevalent in many parts of the world, with the organism being transmitted through infected fleas from rodent reservoirs to humans (2). Human is an accidental host and can carry bubonic plague if contacted by a flea containing plague bacilli. Bubonic plague can develop into septicemic plague or a secondary pneumonic plague if not treated in time. Besides, plague can also be contracted by direct transmission through aerosols to cause an extremely lethal form of primary pneumonic plague. Yersinia pestis exhibits intrinsic genetic plasticity $(3,4)$, can attain antibiotic resistance (5-8), and has been used as a biowarfare agent (9-11). Therefore, Centers for Disease Control has listed $Y$. pestis under the category A select agent.

To date, there is no approved vaccine against plague in the developed world, a live vaccine made in 1920s, has been used by many countries for immunization (12). Early diagnosis can help in the treatment of plague patients with antibiotics; however, there are few reports which confirm the existence of antibiotic resistance strains of $Y$. pestis $(5,6)$. Recently, naturally harboring multidrug resistance variants of $Y$. pestis have been isolated in Mongolia (13). The whole genome sequencing studies showed very less difference between the current circulating strain of $Y$. pestis and the strain responsible for fourteenth century pandemic (14). Moreover, it is quite evident that Y. pestis can be converted into a multidrug-resistant strain by genetic manipulations in the laboratory $(6,15)$. Taking into account of these factors, i.e., rapid progression of the disease and $100 \%$ mortality rate of pneumonic plague, a potential biowarfare agent and the emergence of multidrug resistant variants of 
plague microbe make imperative to develop an ideal and effective vaccine against this highly fatal disease.

\section{CONCEPT TO DEVELOP PLAGUE VACCINES}

Yersinia pestis suppresses the immunity and survives in susceptible hosts, but this capability of the pathogen cannot be applied on infection-survived animals because their immune system resists the re-infection (16). This specific skill of the host to defend against re-infection opened up the opportunities and new avenues to develop vaccine/s to confer protection against this lethal disease.

\section{WHOLE-CELL-BASED VACCINES AGAINST PLAGUE}

The idea to develop vaccine against plague started by Alexandre Yersin in 1895 who investigated immunity against $Y$. pestis in small animal models in his laboratory. He evaluated heat-killed whole-cell vaccine, attenuated live strains of $Y$. pestis, by immunization in animals with repeated boosters (17). These findings encouraged researchers to develop two types of vaccines, i.e., killed whole cell (KWC)- or live whole cell (LWC)-based vaccines modified from virulent strains of $Y$. pestis. To prepare the KWC vaccine, $Y$. pestis bacilli were inactivated either by heating or using chemicals. These vaccines were found safe and evoked immunity against bubonic plague but found inefficient against pneumonic plague in primed animal models (18). Later, Meyer and colleagues developed a more advanced formalin-killed whole-cell vaccines $(19,20)$. A vaccine (USP) developed by this method was approved in USA. Human immunization with formalin-killed, whole-cell vaccine during the Vietnam War indirectly proved that this vaccine protects against bubonic plague $(19,21)$. On the other hand, this vaccine was not only highly reactogenic and inefficient to provide long-term protection but also fail to protect against pneumonic plague $(19,20,22,23)$. Therefore, these killed whole-cell-based vaccines are not appreciable for use against biothreat scenario.

Live whole cell-based vaccines were prepared from fully virulent strains of $Y$. pestis after multiple passages. These types of vaccines were able to induce strong immune response against both types of plague: bubonic and pneumonic. But there is always a risk associated with these vaccines regarding the ability of live bacilli to colonize and temporarily replicate in host. Many fatal cases were seen in laboratory animal models and in non-human primates (NHPs), after vaccination with live vaccines $(19,20)$. However, there was no fatal human case reported after administration of LWC plague vaccine for many years. Even though, millions of people were vaccinated with the LWC in the middle of twentieth century (24), the countries of the former Soviet Union and China are still using LWC-based vaccine against plague for human vaccination. The potential of LWC-based vaccines have been confirmed in humans for many years; however, these vaccines are associated with several adverse effects, and leg behind to provide long-term immunity $(12,25)$.

\section{STRATEGIES FOR THE DEVELOPMENT OF SUBUNIT PLAGUE VACCINE}

With the advent of recombinant DNA technology, immunodominant and protective antigens can be easily identified and prepared in purified form for the development of subunit vaccines. Most importantly, these subunit vaccines reduced the risk factors and adverse effects associated with live and KWC vaccines. However, thorough clinical trials are compulsory to confirm that these vaccines are superior and safe in comparison to whole-cell-based vaccines.

Mainly two virulent factors, capsular F1 and the low calcium response LcrV antigens of $Y$. pestis, have been demonstrated by various researchers throughout the world and proven to be the best to provide protection in various animal models. Immunization with recombinant F1 imparts same degree of protection in mice against subcutaneous or pneumonic plague as does native F1, extracted from $Y$. pestis (26). In our studies (27), vaccination with recombinant F1 failed to protect mice against bubonic plague. Nevertheless, there exist some virulent strains of F1-negative $Y$. pestis; hence, vaccines based exclusively on F1 are not worthwhile against any type of plague (28). In 2011, Chopra's group generated $\Delta$ caf mutant $Y$. pestis in the laboratory by homologous recombination and proven the virulence in a mouse model. The $\Delta$ caf mutant was observed as virulent as WT CO92 in the pneumonic plague (29). In case of LcrV, immunization with both native purified and recombinant $\mathrm{LcrV}$ provides protection in mice against bubonic and pneumonic plague (30, 31). Rabbit polyclonal IgG against an engineered fusion peptide, PAV, provided excellent passive immunity (100\% protection) against intravenous (i.v.) challenge of $Y$. pestis and Yersinia pseudotuberculosis in Swiss Webster mice $(32,33)$. We also reported that recombinant $\mathrm{LcrV}$ alone provided only $75 \%$ protection in mice against bubonic plague (27). The combination of recombinant F1 and LcrV antigens elicited greater protection in comparison to either $\mathrm{F} 1$ alone or $\operatorname{LcrV}$ alone $(34,35)$. Vaccination with F1 and LcrV antigens adjuvanted with alum protects mice against pneumonic plague, proven by The United Kingdom's defense department $(36,37)$. The United States Army Medical Research Institute of Infectious Diseases demonstrated that a recombinant bivalent $\mathrm{F} 1-\mathrm{LcrV}$ fusion protein provides protection in mice challenged via aerosolized route against virulent strains of $Y$. pestis $(26,38)$. In a recent study, F1mut-V in formulation with alhydrogel and T4-decorated F1mut-V without any adjuvant imparted $100 \%$ protection in mice and rats against pneumonic plague (39). In our recent studies, we also demonstrated that a mixture of recombinant $\mathrm{F} 1+\mathrm{LcrV}$ antigens in formulation with alum imparts full protection in mice against bubonic plague (27). In conclusion, F1/LcrV vaccine provides strong protective immunity in mice, rats, and rabbits against subcutaneous and pneumonic plague. The vaccine mainly induced humoral immune response as a high titer of anti-LcrV antibodies is very crucial. The protection is stimulated by anti-LcrV antibodies, which help by blocking the type 3 secretion system $(40,41)$. Inclusion of F1 with LcrV enhanced the protection as $\mathrm{LcrV}$ does not always provide $100 \%$ protection (27). 
Due to the ethical limitations, it is not possible to challenge human with Y. pestis; hence, the NHPs or monkeys are considered as standard model for trials of plague vaccines. The intramuscular vaccination of $\mathrm{F} 1 / \mathrm{V}$ vaccines in formulation with alhydrogel protects cynomolgus macaques against pneumonic plague $(42,43)$; however, this $\mathrm{F} 1-\mathrm{LcrV}$ vaccine provided poor and inconsistent $(0-75 \%)$ protection in African green monkeys (44-46). The F1/LcrV vaccine also provided protection against subcutaneous challenge of virulent $Y$. pestis in rhesus macaques (47) and baboons (48). The existence of F1-negeative virulent strains of plague bacilli $(12,49)$ and $\operatorname{LcrV}$ variants of $Y$. pestis $(50,51)$ may not be ignored to not to confer the cross protection. The subunit vaccine exclusively based on F1/LcrV may not be worthwhile for a biothreat scenario, hence, the inclusion of additional subunits to the F1/LcrV vaccine is utmost needed. Vaccination with recombinant YscF in formulation with Freund's adjuvant protected mice from an i.v. challenge with $Y$. pestis (52). In another study, immunization with recombinant YscF in formulation with Ribi adjuvant system R-730 monophosphoryl lipid A provided significant protection in mice against subcutaneous challenge with Y.pestis (53). In a recent study, anti-Ail/OmpX and anti-OmpA antibodies protected mice against bubonic plague, and anti-Pla antibodies were protective against pneumonic when challenged with the F1-negative CO92 strain (54). In the past, a number of antigens have been evaluated for protection with very little success (45).

\section{ROLE OF MOLECULAR ADJUVANTS}

The ultimate goal of vaccination is to stimulate a strong and long-lasting immunity to the administered subunit candidate against infection. Generally, the problem associated with purified recombinant subunit vaccine candidates is the poor/lessinduced immunogenicity in comparison to LWC- or KWC-based vaccines. To deal with this problem, alum is the one and only approved human compatible adjuvant and has been used for human vaccination widely, but alum mainly stimulates the Th2 response. The important facts to use adjuvants are (1) to augment the immune response of purified recombinant subunits, (2) to improve the protective potential, (3) to decrease the amount of dose and number of vaccination, and (4) to help in delivery of an antigen to the target cells (55-57).

The immunization of mice with $\mathrm{F} 1$ and LcrV antigens in formulation with molecular adjuvants, i.e., cholera toxin and heat-labile enterotoxin (LT), both formulations provided partial protection against $100 \mathrm{MLD}$ against a virulent strain of $Y$. pestis (58). Flagellin, agonist of toll-like receptor-5, is mostly used molecular adjuvant with F1-LcrV to augment the Th1 type of immune response and provided $100 \%$ protection in mice against a respiratory challenge with $Y$. pestis $(46,59)$ and showed variable protective efficacy in NHPs against pneumonic challenge (46). CpG Oligodeoxynucleotides, agonist of TLR-9, elicit a balance Th1/Th2 response in formulation with F1-LcrV fusion protein and protected mice against bubonic and pneumonic plague (60, 61). Microencapsulation (62) and lipid A mimetics (63) of recombinant LcrV-F1 fusion protein induced a mixed Th1/Th2 cell-mediated immune response and provided protection against pneumonic plague in mice and rats. Liposome, such as cationic liposome nucleic acid complexes (64), and proteosomes, such as protollin (65), have been evaluated with F1-LcrV and have been shown to protect against pneumonic plague.

In 2013, Tao et al. addressed a series of concerns and generated mutants of F1 and V, which are completely soluble and produced in high yields. The authors engineered the vaccine into a novel delivery platform using the bacteriophage T4 nanoparticle. The nanoparticle vaccines induced strong immune response and conferred $100 \%$ protection against pneumonic plague in mice and rats (39). Some novel agonist of the costimulatory molecules of tumor necrosis factor receptor super family has been shown to stimulate $\mathrm{T}$ cell activation, expansion, and acquisition of effector function. One such molecule, SA-4-1BBL (recombinant agonist of 4-1-BB costimulatory molecule), had shown a better efficacy in generating $\mathrm{CD}^{+}$and $\mathrm{CD}^{+} \mathrm{T}$ cells producing TNF- $\alpha$ and IFN- $\gamma$ with F1-LcrV fusion protein and provided $100 \%$ protection against bubonic model of plague in $\mathrm{C} 57 \mathrm{BL} / 6$ mice (66). Addition of HSP70 (domain II) of Mycobacterium tuberculosis with F1/LcrV subunits of $Y$. pestis augments the cellular immune response. HSP70(II) significantly elevated the levels of IL-2, IFN- $\gamma$, TNF- $\alpha$, and IFN- $\gamma$ secreting CD $4^{+} / \mathrm{CD}^{+} \mathrm{T}$ cells in F1 + LcrV + HSP70(II) vaccinated group in comparison to the F1 + LcrV group. F1 + LcrV + HSP70(II) combination provided full protection against virulent strain of $Y$. pestis ( $\mathrm{S} 1$, Indian clinical isolate) in a mouse model (27). Later, we designed a recombinant trivalent fusion protein F1-LcrV-HSP70(II) and evaluated in a mouse model. This trivalent fusion protein provides improved cellular immune response and full protection against plague (67). Overall, the molecular adjuvants play the crucial role in vaccine development from antigen delivery to augmentation of the immune response in the host.

\section{DNA VACCINES STRATEGIES}

Attempts were made to develop recombinant DNA vaccines against plague. Initially, the success rate was low as generating weak humoral immune response to F1 and LcrV. The LcrV/F1-based DNA vaccines were developed as an alternative approach to protein-based vaccines that contain either full or part of the open reading frames encoding LcrV, F1, or both. A peptide (127-amino acid) vaccine of LcrV antigen elicited a strong humoral immune response and provided $60 \%$ protection against $Y$. pestis in mice (68). The addition of the constructs of molecular immunopotentiator IL-12 with F1 or LcrV has significantly enhanced the immune response and showed $80 \%$ protection from a subsequent inhalational challenge with $Y$. pestis (69). The DNA constructs were prepared to express the $Y$. pestis antigens with human tissue plaminogen activator (tPA) signal sequence to get the secretory proteins in absolutely soluble forms. DNA vaccination of $\mathrm{LcrV}$ with tPA elicited a significant humoral immune response and protected against pneumonic plague (70). In a recent study, DNA vaccine of $\mathrm{LcrV}$ elicited a robust $\mathrm{CD} 8^{+} \mathrm{T}$ cell immune response against specific epitopes (71). Some other vaccine candidates, i.e., YscF, Pla, YopB, YopD, and YpkA, were also evaluated in small animals and showed inadequate protection (72). In conclusion, the result of DNA vaccination was highly reliant upon the DNA 
vaccine construct, and this technology must be encouraged and optimized for future use of human vaccination against plague.

\section{LIVE CARRIER PLATFORMS FOR VACCINE DELIVERY}

Apart from the testing of plague subunit vaccines, the expression of vaccine candidates from $Y$. pestis in live carriers also started. These types of systems have their own limitations, because the expertise of attenuation is needed when virulent genes are expressed as protective antigens. Attenuation is an important step because a huge risk is associated particularly for immunocompromised populations. It is very important to know that how to prepare and store the vaccine stockpile in order to make sure the viability of the vector for delivery. Nevertheless, the advantage of the live vaccines is the low cost, easy to scale-up the production, and the potential to induce strong cell-mediated and mucosal immune response.

\section{LIVE VIRAL-BASED DELIVERY PLATFORMS}

Replication-deficient adenoviral vectors (Ad) are well-established delivery platforms as they transfer gene/s efficiently to the macrophages following their activation, and therefore evoking robust and fast humoral and cellular immunity. An adenovirus (Ad) gene-transfer vector encoding $\mathrm{LcrV}$ vaccine candidate was developed by Crystal's group $(73,74)$. Single immunization with this recombinant virus was found efficient to induce strong humoral and cellular immunity and provided protection against pneumonic plague in mice $(73,74)$. Later, they linked either LcrV or F1 vaccine candidate to the capsid protein pIX of adenovirus and demonstrated that both constructs induced significantly robust IgG response in the sera of intramuscular (i.m.)-vaccinated mice in comparison to the vaccination with purified LcrV/F1 in formulation with adjuvant $(73,74)$. Recently, a replication-defective human type 5 adenovirus (Ad5) vector was used to construct the recombinant monovalent and trivalent vaccines ( $\mathrm{rAd} 5-\mathrm{LcrV}$ and $\mathrm{rAd} 5-\mathrm{YFV}$ ). The monovalent codon-optimized $l c r V$ gene expressed LcrV and the trivalent fusion gene-designated $Y F V$ expressed a trivalent fusion protein YscF-F1-LcrV. Vaccination of mice with the trivalent rAd5YFV construct provided superior protection in comparison to monovalent rAd5-LcrV construct against bubonic and pneumonic when challenged via either the i.m. or the intranasal (i.n.) route. Immunization of cynomolgus macaques with the trivalent rAd5-YFV provided $100 \%$ protection against pneumonic plague. This has first ever proved the efficacy of an adenovirus-vectored trivalent $\mathrm{rAd} 5$-YFV vaccine against pneumonic plague in mouse and NHP models (75).

One more vaccine based on recombinant vesicular stomatitis virus vectors harboring the gene encoding LcrV antigen was developed and evaluated in mice by Rose's group $(76,77)$. The genes encoding LcrV and F1 were cloned in Vaccinia viral-based vectors and evaluated in Balb/C mice. The observed response was significantly immunogenic, and vaccine was found safe in immunocompromised SCID mice $(78,79)$. It was reported in a study that latent infection with either murine gammaherpesvirus 68 or murine cytomegalovirus in mice provides protection against Listeria monocytogenes or Y. pestis challenge via both routes either intranasal or subcutaneous. The mechanism of protection was the long-lasting expression of interferon- $\gamma$ and activation of antigen-presenting cells, which evoked the innate immunity against challenge of $Y$. pestis (80). The scientists of National Wildlife Health Center, USA, evaluated Racoon poxvirus (RCN)-based two vaccine constructs, RCN-F1 and RCN-V307. The consumption of baits containing both vaccine constructs, i.e., RCN-F1 and RCN-V307, by prairie dogs (Cynomys ludovicianus) showed significant protection against plague challenge (81). Later, the same group evaluated a dual RCN-F1/V307 construct that expresses both F1 and V307 antigens. The RCN-F1/V307 vaccine imparted similar degree of protection against plague not only in mice but also in prairie dogs as compared to single antigen constructs. The RCN-F1/ V307 vaccine also provided protection in mice against an F1-negative strain of $Y$. pestis $(82,83)$.

\section{LIVE BACTERIALLY BASED DELIVERY PLATFORMS}

An attenuated Salmonella was used first ever as a live delivery platform to express F1 and LcrV antigens. In orally vaccinated animals, these vaccines induced the expression of IgG2a subtypes and found inefficient to protect against plague. Immunization via nasal route and boosting with purified antigens via parenteral could be the better approach to augment the immunity. Still, the protection was significantly less in comparison to protection provided by immunization with recombinant antigens (49). Several studies have been performed by Titball's group; they designed and prepared to express the bivalent F1-LcrV fusion protein (84), LcrV only (85), and F1 on cell surface (86). A Salmonella strain was constructed to express F1 as an extracellular capsule and soluble LcrV antigen (87). Largely, S. Typhimurium strains expressing F1/LcrV or truncated LcrV were performed to evoke the IgG- and cell-mediated immune response to the protein of interest. These vaccines provide partial protection against $Y$. pestis infection via nasal or subcutaneous route.

Morton et al. studied a S. Typhi strain expressing F1 provided protection in mice after intranasal vaccination against plague (88). One similar type of vaccine strain was also performed in 7 -day-old mice after immunization via intranasal route (89). The vaccinated animals developed mucosal immune response, and IFN- $\boldsymbol{\gamma}$-expressing cells and were primed with F1 in formulation with alum. This Salmonella vaccine offered strong priming in comparison to F1 with alum prime, proving the better efficiency of Salmonella-based vaccine for plague in a prime boost setting. Newly invented vectors derived from Salmonella with better immunogenicity, controlled mechanism of attenuation, and longterm stability in expression of antigens of interest has endorsed the improved protective potentials of vaccine mainly based on the tailored LcrV (90). The degree of immunity of this vaccine is not as good as induced by the purified F1 and LcrV vaccines. However, 
Salmonella-vectored system is quite appropriate to express the outer membrane proteins, i.e., PsaA, adhesin, and HmuR, which have been evaluated as vaccine candidates $(91,92)$. There is one more report where LcrV antigen from Y. pseudotuberculosis was expressed in a heterologous delivery system; the commensal, nonpathogenic species Lactococcus lactis. This L. lactis expressing LcrV did not protect against $Y$. pestis; however, it protected well against $Y$. pseudotuberculosis (93). In a recent study, intranasal immunization of mice with $L$. lactis secreting LcrV antigen from Y. pseudotuberculosis (Ll-LcrV) induced strong humoral and cellular immunity against $Y$. pseudotuberculosis infection in a mouse model and provided a significant long-lasting protection (94).

A remarkable progress has been made by Carniel's group on developing plague vaccine using avirulent $Y$. pseudotuberculosis. Vaccination against bubonic plague can be obtained using attenuated Y. pseudotuberculosis (strain IP32680). One oral IP32680 inoculation provided $75 \%$ protection and two inoculations provided $88 \%$ protection against subcutaneous challenge with Y. pestis $\mathrm{CO} 92$ in a mouse model (95). The similar group generated an encapsulated $Y$. pseudotuberculosis by cloning the F1 encoding caf operon of $Y$. pestis. A single oral vaccination with the live attenuated Y. pseudotuberculosis V674pF1 imparted significant protection against pneumonic plague in mice (96). Later, the caf operon was manipulated into the chromosome of a genetically attenuated Y. pseudotuberculosis, yielding the VTnF1 strain. A single dose by oral administration of VTnF1 vaccine provided $100 \%$ protection against both bubonic and pneumonic plague in mice. The authors claimed that VTnF1 strain is easy-to-produce, genetically stable, and irreversibly attenuated and provides longlasting immunity against both wild-type and F1-negative $Y$. pestis $(97,98)$.

\section{ATTENUATED PLAGUE VACCINES}

An attenuated vaccine is created by reducing the virulence of a pathogen, but still keeping it live. Attenuation takes an infectious agent and alters it so that it becomes avirulent. In 1936, a human live plague vaccine developed from an attenuated strain EV NIIEG of $Y$. pestis has been extensively used in Russia. This is a subculture of vaccine strain EV76, developed at the NIIEG (Scientific-Research Institute for Epidemiology and Hygiene, Kirov, Russian Federation) in the former USSR (17, 99). EV NIIEG is the only approved vaccine against plague for human use during plague outbreaks. The short-term immunity and the concern of safety are the limitations of this vaccine. Additionally, LPV provides poor protection to mice against non-encapsulated $Y$. pestis challenge (25). The vaccination showed several side effects due to its highly toxic nature. The vaccine EV NIIEG was modified by removing the lp $x M$ gene for the late acyltransferase, resulting in formation of predominantly less-toxic penta-acylated lipid A. The modified mutant vaccine conferred better protection in mice and guinea pigs due to the optimal expression of protective antigens and its long-lasting existence in immunized animals $(100,101)$. Another approach used by Y. pestis expresses tetraacylated lipid A that can not activate TLR-4 so that the pathogen can breach the host immune system. This is happened because both the $l_{p} x P$ and $l_{p} x M$ genes expresses hexa-acylated lipid $\mathrm{A}$ at $28^{\circ} \mathrm{C}$. Both LpxP and LpxM are important for hexa-acylation. But at $37^{\circ} \mathrm{C}$, in human host, $l_{p x P}$ is not stimulated to express, which results in tetra-acylated lipid A. TLR-4 does not recognize tetra-acylated lipid A (102). TLR-4 recognizes hexa-acylated lipid A (103-105). Researchers introduced the lpxL gene of $E$. coli expressing acyltransferase absent in Y. pestis. The engineered strain constitutively expressed hexa-acylated lipid A that evokes the innate immune system at the early hours of $Y$. pestis infection leading to its elimination (106).

Another successful strategy is to attenuate the wild-type strain of Y.pestis to develop the vaccine. Therefore, the attenuated strains carrying the mutations in the $l p p$ and $n l p D$ genes encoding outer membrane lipoproteins showed outstanding capability to induce protective immune response against $Y$. pestis $(107,108)$. A deletion in the global regulator gene rovA of $Y$. pestis was introduced and tested as a vaccine candidate (109). Likewise, a number of mutations in wild-type strain of $Y$. pestis were introduced to diminish the virulence. Many mutant strains were evaluated for their protective efficacy, which were having the mutations in the genes, i.e., yopH encoding effector protein of type 3 secretion system; aro $A$ gene for aromatic-dependent; guaB gene encoding for guanine nucleotide bio-sysnthesis; crp gene encoding for cyclic adenosine monophosphate receptor protein; relA and spoT genes; smpB-ssr $A$ genes encoding housekeeping functions for the translational machinery; and dam gene for DNA adenine methylase $(92,110)$.

\section{FUTURE PERSPECTIVE}

The F1/LcrV-based subunit vaccine mainly induces a humoral immune response. While this vaccine has shown promising results in animal models, its protective potential in humans is yet to be assessed. In the near future, the F1/LcrV-based vaccine may be accessible to populations residing in plagueendemic areas. Since the protective effect of this vaccine is mainly dependent on humoral immunity, it may be essential to administer boosters from time to time. Next-generation plague vaccines should be designed to stimulate strong cell-mediated immunity as well. Both of the responses, humoral and cellular, effectively contribute to vaccine efficiency. The humoral immune response refers to the production of antibodies that neutralize extracellular microbes, while the cellular immune response relies on $\mathrm{T}$ cells which express cytokines and actively destroy intracellular microbes. The heat-shock protein 70 (domain II) of $M$. tuberculosis and SA-4-1BBL (recombinant agonist of 4-1$\mathrm{BB}$ costimulatory molecule) modulate cellular immunity and have been used to enhance the protective potential of F1/LcrV antigens in mice; however these studies need further evaluation in NHPs $(27,66)$.

In USA, existing KWC or live attenuated vaccines against plague are presently not preferred due to ethical concerns. As a result, a prime boost strategy to improve the protective capacity of next-generation DNA or live carrier vaccines would be of immense interest $(92,110)$. Reasonably, live attenuated $Y$. pestis strains stimulated complete protection against plague in animal models. Current live $Y$. pestis vaccines must stimulate both humoral- and cell-mediated immunity to a range of important 
antigens, imparting robust protection, especially in comparison to the subunit vaccines. Thus, there is an urgent need to extend research for the development of new innovations and improved version of live attenuated vaccines.

\section{AUTHOR CONTRIBUTIONS}

SV collected the literature and prepared the manuscript, and UT reviewed and edited the manuscript.

\section{REFERENCES}

1. Perry RD, Fetherston JD. Yersinia pestis - etiologic agent of plague. Clin Microbiol Rev (1997) 10:35-66.

2. Gage KL, Kosoy MY. Natural history of plague: perspectives from more than a century of research. Annu Rev Entomol (2005) 50:505-28. doi:10.1146/ annurev.ento.50.071803.130337

3. Guiyoule A, Rasoamanana B, Buchrieser C, Michel P, Chanteau S, Carniel E. Recent emergence of new variants of Yersinia pestis in Madagascar. J Clin Microbiol (1997) 35:2826-33.

4. Radnedge L, Agronx PG, Worsham PL, Andersen GL. Genome plasticity in Yersinia pestis. Microbiology (2002) 148:1687-98. doi:10.1099/ 00221287-148-6-1687

5. Galimand M, Guiyoule A, Gerbaud G, Rasoamanana B, Chanteau S, Carniel E, et al. Multidrug resistance in Yersinia pestis mediated by a transferable plasmid. N Engl J Med (1997) 337:677-80. doi:10.1056/NEJM19970904 3371004

6. Guiyoule A, Gerbaud G, Buchrieser C, Galimand M, Rahalison L, Chanteau $S$, et al. Transferable plasmid-mediated resistance to streptomycin in a clinical isolate of Yersinia pestis. Emerg Infect Dis (2001) 7:43-8. doi:10.3201/ eid0701.700043

7. Hinnebusch BJ, Rosso ML, Schwan TG, Carniel E. High-frequency conjugative transfer of antibiotic resistance genes to Yersinia pestis in the flea midgut. Mol Microbiol (2002) 46:349-54. doi:10.1046/j.1365-2958.2002. 03159.x

8. Welch TJ, Fricke WF, McDermott PF, White DG, Rosso ML, Rasko DA, et al. Multiple antimicrobial resistance in plague: an emerging public health risk. PLoS One (2007) 2:e309. doi:10.1371/journal.pone.0000309

9. Alibek K. Biohazard. New York: Random House, Inc (1999).

10. Dennis DT. Bioterrorism and infectious agents: a new dilemma for the 21 st century. In: Fong IW, Alibek K, editors. Plague as a Biological Weapon. New York: Springer Science (2005). p. 37-64.

11. Zilinskas RA. The anti-plague system and the Soviet biological warfare program. Crit Rev Microbiol (2006) 32:47-64. doi:10.1080/10408410500496896

12. Feodorova VA, Corbel MJ. Prospects for new plague vaccines. Expert Rev Vaccines (2009) 8:1721-38. doi:10.1586/erv.09.129

13. Kiefer D, Dalantai G, Damdindorj T, Riehm JM, Tomaso H, Zöller L, et al. Phenotypical characterization of Mongolian Yersinia pestis strains. Vector Borne Zoonotic Dis (2012) 12:183-8. doi:10.1089/vbz.2011.0748

14. Bos KI, Schuenemann VJ, Golding GB, Burbano HA, Waglechner N, Coombes BK, et al. A draft genome of Yersinia pestis from victims of the black death. Nature (2011) 478:506-10. doi:10.1038/nature10549

15. Butler T. Plague gives surprises in the first decade of the $21^{\text {st }}$ century in the United States and worldwide. Am J Trop Med Hyg (2013) 89:788-93. doi:10.4269/ajtmh.13-0191

16. Pollitzer R. Plague. Geneva: World Health Organization (1954).

17. Girard G. Immunity in plague infection: results of 30 years of work with the Pasteurella pestis EV strain (Girard and Robic). Biol Med (Paris) (1963) 52:631-631.

18. Russell P, Eley SM, Hibbs SE, Manchee RJ, Stagg AJ, Titball RW. A comparison of plague vaccine, USP and EV76 vaccine induced protection against Yersinia pestis in a murine model. Vaccine (1995) 13:1551-6. doi:10.1016/0264-410X(95)00090-N

19. Meyer KF. Effectiveness of live or killed plague vaccines in man. Bull World Health Organ (1970) 42:653-66.

\section{ACKNOWLEDGMENTS}

The authors are thankful to Director, Defence Research \& Development Establishment (DRDE), Ministry of Defence, Govt. of India for providing the necessary facilities.

\section{FUNDING}

DRDE (DRDO) is the funding institute for this work.

20. Meyer KF, Cavanaugh DC, Bartelloni PJ, Marshall JD Jr. Plague immunization. I. Past and present trends. J Infect Dis (1974) 129:S13-8. doi:10.1093/ infdis/129.Supplement_1.S13

21. Cavanaugh DC, Elisberg BL, Llewellyn CH, Marshall JD Jr, Rust JH Jr, Williams JE, et al. Plague immunization. V. Indirect evidence for the efficacy of plague vaccine. J Infect Dis (1974) 129:S37-40. doi:10.1093/infdis/129. Supplement_1.S37

22. Cohen RJ, Stockard JL. Pneumonic plague in an untreated plague-vaccinated individual. JAMA (1967) 202:365-6. doi:10.1001/jama.202.4.365

23. Titball RW, Williamson ED. Yersinia pestis (plague) vaccines. Expert Opin Biol Ther (2004) 4:965-73. doi:10.1517/14712598.4.6.965

24. Korobkova EI. Live Anti-Plague Vaccine. Moscow: Medgiz (1956).

25. Feodorova VA, Sayapina LV, Corbel MJ, Motin VL. Russian vaccines against especially dangerous bacterial pathogens. Emerg Microbes Infect (2014) 12:e86. doi:10.1038/emi.2014.82

26. Andrews GP, Heath DG, Anderson GW Jr, Welkos SL, Friedlander AM. Fraction 1 capsular antigen (F1) purification from Yersinia pestis CO92 and from an Escherichia coli recombinant strain and efficacy against lethal plague challenge. Infect Immun (1996) 64:2180-7.

27. Batra L, Verma SK, Nagar DP, Saxena N, Pathak P, Pant SC, et al. HSP70 domain II of Mycobacterium tuberculosis modulates immune response and protective potential of F1 and LcrV antigens of Yersinia pestis in a mouse model. PLoS Negl Trop Dis (2014) 8:e3322. doi:10.1371/journal.pntd.0003322

28. Worsham PL, Stein MP, Welkos SL. Construction of defined F1 negative mutants of virulent Yersinia pestis. Contrib Microbiol Immunol (1995) 13:325-8.

29. Sha J, Endsley JJ, Kirtley ML, Foltz SM, Huante MB, Erova TE, et al. Characterization of an F1 deletion mutant of Yersinia pestis CO92, pathogenic role of $\mathrm{F} 1$ antigen in bubonic plague and pneumonic plague, and evaluation of sensitivity and specificity of F1 antigen capture-based dipsticks. JClin Microbiol (2011) 5:1708-15. doi:10.1128/JCM.00064-11

30. Anderson GW Jr, Leary SE, Williamson ED, Titball RW, Welkos SL, Worsham $\mathrm{PL}$, et al. Recombinant $\mathrm{V}$ antigen protects mice against pneumonic and bubonic plague caused by F1-capsule-positive and negative strains of $Y$. pestis. Infect Immun (1996) 64:4580-5.

31. Anderson GW Jr, Heath DG, Bolt CR, Welkos SL, Friedlander AM. Shortand long-term efficacy of single-dose subunit vaccines against Yersinia pestis in mice. Am J Trop Med Hyg (1998) 58:793-9.

32. Motin VL, Nakajima R, Smirnov GB, Brubaker RR. Passive immunity to yersiniae mediated by anti-recombinant $\mathrm{V}$ antigen and protein $\mathrm{A}-\mathrm{V}$ antigen fusion peptide. Infect Immun (1994) 10:4192-201.

33. Nakajima R, Motin VL, Brubaker RR. Suppression of cytokines in mice by protein $\mathrm{A}-\mathrm{V}$ antigen fusion peptide and restoration of synthesis by active immunization. Infect Immun (1995) 8:3021-9.

34. Williamson ED, Eley SM, Griffin KF, Green M, Russell P, Leary SE, et al. A new improved sub-unit vaccine for plague: the basis of protection. FEMS Immunol Med Microbiol (1995) 12:223-30. doi:10.1111/j.1574-695X.1995. tb00196.x

35. Williamson ED, Sharp GJ, Eley SM, Vesey PM, Pepper TC, Titball RW, et al. Local and systemic immune response to a microencapsulated subunit vaccine for plague. Vaccine (1996) 14:1613-9. doi:10.1016/S0264-410X(96)00151-X

36. Williamson ED, Eley SM, Stagg AJ, Green M, Russell P, Titball RW. A subunit vaccine elicits IgG in serum, spleen cell cultures and bronchial washings and protects immunized animals against pneumonic plague. Vaccine (1997) 15:1079-84. doi:10.1016/S0264-410X(96)00303-9 
37. Jones SM, Day F, Stagg AJ, Williamson ED. Protection conferred by a fully recombinant sub-unit vaccine against Yersinia pestis in male and female mice of four inbred strains. Vaccine (2000) 19:358-66. doi:10.1016/ S0264-410X(00)00108-0

38. Heath DG, Anderson GW Jr, Mauro JM, Welkos SL, Andrews GP, Adamovicz J, et al. Protection against experimental bubonic and pneumonic plague by a recombinant capsular F1-V antigen fusion protein vaccine. Vaccine (1998) 16:1131-7. doi:10.1016/S0264-410X(98)80110-2

39. Tao P, Mahalingam M, Kirtley ML, van Lier CJ, Sha J, Yeager LA, et al. Mutated and bacteriophage T4 nanoparticle arrayed F1-V immunogens from Yersinia pestis as next generation plague vaccines. PLoS Pathog (2013) 9:e1003495. doi:10.1371/journal.ppat.1003495

40. Eisele NA, Anderson DM. Dual-function antibodies to Yersinia pestis LcrV required for pulmonary clearance of plague. Clin Vaccine Immunol (2009) 12:1720-7. doi:10.1128/CVI.00333-09

41. Quenee LE, Berube BJ, Segal J, Elli D, Ciletti NA, Anderson D, et al. Amino acid residues 196-225 of LcrV represent a plague protective epitope. Vaccine (2010) 7:1870-6. doi:10.1016/j.vaccine.2009.11.076

42. Cornelius CA, Quenee LE, Overheim KA, Koster F, Brasel TL, Elli D, et al. Immunization with recombinant V10 protects cynomolgus macaques from lethal pneumonic plague. Infect Immun (2008) 76:5588-97. doi:10.1128/ IAI.00699-08

43. Williamson ED, Packer PJ, Waters EL, Simpson AJ, Dyer D, Hartings J, et al. Recombinant $(\mathrm{F} 1+\mathrm{V})$ vaccine protects cynomolgus macaques against pneumonic plague. Vaccine (2011) 29:4771-7. doi:10.1016/j.vaccine.2011.04.084

44. Pitt ML. Non-Human Primates as a Model for Pneumonic Plague; Animal Models and Correlates of Protection for Plague Vaccines Workshop. Gaithersburg, MD (2004). p. 13-4. Available from: http://www.fda.gov/cber/ minutes/workshop-min.htm

45. Smiley ST. Immune defense against pneumonic plague. Immunol Rev (2008) 225:256-71. doi:10.1111/j.1600-065X.2008.00674.x

46. Mizel SB, Graff AH, Sriranganathan N, Ervin S, Lees CJ, Lively MO, et al. Flagellin-F1-V fusion protein is an effective plague vaccine in mice and two species of nonhuman primates. Clin Vaccine Immunol (2009) 16:21-8. doi:10.1128/CVI.00333-08

47. Qiu Y, Liu Y, Qi Z, Wang W, Kou Z, Zhang Q, et al. Comparison of immunological responses of plague vaccines F11rV270 and EV76 in Chinese-origin rhesus macaque, Macaca mulatta. Scand J Immunol (2010) 72:425-33. doi:10.1111/j.1365-3083.2010.02456.x

48. Stacy S, Pasquali A, Sexton VL, Cantwell AM, Kraig E, Dube PH. An age-old paradigm challenged: old baboons generate vigorous humoral immune responses to LcrV, a plague antigen. J Immunol (2008) 181:109-15. doi:10.4049/jimmunol.181.1.109

49. Feodorova VA, Motin VL. Plague vaccines. In: Feodorova VA, Motin VL, editors. Vaccines Against Bacterial Biothreat Pathogens. Kerala: Research Signpost (2011). p. 176-233.

50. Motin VL, Pokrovskaya MS, Telepnev MV, Kutyrev VV, Vidyaeva NA, Filippov AA, et al. The difference in the lcrV sequences between Yersinia pestis and Yersinia pseudotuberculosis and its application for characterization of Y. pseudotuberculosis strains. Microb Pathog (1992) 12:165-75. doi:10.1016/0882-4010(92)90050-X

51. Anisimov AP, Dentovskaya SV, Panfertsev EA, Svetoch TE, Kopylov PKh, Segelke BW, et al. Amino acid and structural variability of Yersinia pestis LcrV protein. Infect Genet Evol(2010) 10:137-45. doi:10.1016/j.meegid.2009.10.003

52. Matson JS, Durick KA, Bradley DS, Nilles ML. Immunization of mice with YscF provides protection from Yersinia pestis infections. BMC Microbiol (2005) 5:38. doi:10.1186/1471-2180-5-38

53. Swietnicki W, Powell BS, Goodin J. Yersinia pestis Yop secretion protein F: purification, characterization, and protective efficacy against bubonic plague. Protein Expr Purif (2005) 1:166-72. doi:10.1016/j.pep.2005.02.016

54. Erova TE, Rosenzweig JA, Sha J, Suarez G, Sierra JC, Kirtley ML, et al. Evaluation of protective potential of Yersinia pestis outer membrane protein antigens as possible candidates for a new-generation recombinant plague vaccine. Clin Vaccine Immunol (2013) 2:227-38. doi:10.1128/CVI.00597-12

55. Marx PA, Compans RW, Gettie A, Staas JK, Gilley RM, Mulligan MJ, et al. Protection against vaginal SIV transmission with microencapsulated vaccine. Science (1993) 260:1323-7. doi:10.1126/science.8493576

56. McElrath MJ. Selection of potent immunological adjuvants for vaccine construction. Semin Cancer Biol (1995) 6:375-85. doi:10.1016/1044-579X (95)90007-1
57. Douce G, Turcotte C, Cropley I, Roberts M, Pizza M, Domenghini M, et al. Mutants of Escherichia coli heat-labile toxin lacking ADP ribosyl-transferase activity act as non-toxic mucosal adjuvants. Proc Natl Acad Sci U S A (1995) 92:1644-8. doi:10.1073/pnas.92.5.1644

58. Eyles JE, Elvin SJ, Westwood A, Lebutt CS, Alpar HO, Somavarapu S, et al. Immunisation against plague by transcutaneous and intradermal application of subunit antigens. Vaccine (2004) 22:4365-73. doi:10.1016/ j.vaccine.2004.02.049

59. Honko AN, Sriranganathan N, Lees CJ, Mizel SB. Flagellin is an effective adjuvant for immunization against lethal respiratory challenge with Yersinia pestis. Infect Immun (2006) 74:1113-20. doi:10.1128/IAI.74.2.1113-1120.2006

60. Amemiya K, Meyers JL, Rogers TE, Fast RL, Bassett AD, Worsham PL, et al. $\mathrm{CpG}$ oligodeoxynucleotides augment the murine immune response to the Yersinia pestis F1-V vaccine in bubonic and pneumonic models of plague. Vaccine (2009) 27:2220-9. doi:10.1016/j.vaccine.2009.02.016

61. Hickey AJ, Lin JS, Kummer LW, Szaba FM, Duso DK, Tighe M, et al. Intranasal prophylaxis with $\mathrm{CpG}$ oligodeoxynucleotide can protect against Yersinia pestis infection. Infect Immun (2013) 81:2123-32. doi:10.1128/IAI.00316-13

62. Gupta G, Khan AA, Rao DN. Cell-mediated immune response and Th1/Th2 cytokine profile of B-T constructs of F1 and V antigen of Yersinia pestis. Scand J Immunol (2010) 71:186-98. doi:10.1111/j.1365-3083.2009.02365.x

63. Airharta CL, Rohdea HN, Hovdea CJ, Bohach GA, Deobald CF, Lee SS, et al. Lipid A mimetics are potent adjuvants for an intranasal pneumonic plague vaccine. Vaccine (2008) 26:5554-61. doi:10.1016/j.vaccine.2008.08.007

64. Jones A, Bosioa C, Duffy A, Goodyear A, Schriefer M, Dow S. Protection against pneumonic plague following oral immunization with a non-replicating vaccine. Vaccine (2010) 28:5924-9. doi:10.1016/j.vaccine.2010.06.020

65. Jones T, Adamovicz JJ, Cyr SL, Bolt CR, Bellerose N, Pitt LM, et al. Intranasal protollin/F1-V vaccine elicits respiratory and serum antibody responses and protects mice against lethal aerosolized plague infection. Vaccine (2006) 24:1625-32. doi:10.1016/j.vaccine.2005.09.052

66. Dinc G, Pennington JM, Yolcu ES, Lawrenz MB, Shirwan H. Improving the Th1 cellular efficacy of the lead Yersinia pestis $\mathrm{rF1}-\mathrm{V}$ subunit vaccine using SA-4-1BBL as a novel adjuvant. Vaccine (2014) 32:5035-40. doi:10.1016/ j.vaccine.2014.07.015

67. Verma SK, Batra L, Tuteja U. A recombinant trivalent fusion protein F1-LcrV-HSP70(II) augments humoral and cellular immune responses and imparts full protection against Yersinia pestis. Front Microbiol (2016) 7:1053. doi:10.3389/fmicb.2016.01053

68. Vernazza C, Lingard B, Flick-Smith HC, Baillie LW, Hill J, Atkins HS. Small protective fragments of the Y. pestis V antigen. Vaccine (2009) 27:2775-80. doi:10.1016/j.vaccine.2009.03.011

69. Yamanaka H, Hoyt T, Yang X, Golden S, Bosio CM, Crist K, et al. A nasal interleukin-12 DNA vaccine co expressing $Y$. pestis F1-V fusion protein confers protection against pneumonic plague. Infect Immun (2008) 76:4564-73. doi:10.1128/IAI.00581-08

70. Wang S, Heilman D, Liu F, Giehl T, Joshi S, Huang X, et al. A DNA vaccine producing LcrV antigen in oligomers is effective in protecting mice from lethal mucosal challenge of plague. Vaccine (2004) 22:3348-57. doi:10.1016/ j.vaccine.2004.02.036

71. Wang S, Goguen JD, Li F, Lu S. Involvement of CD8+ T cell-mediated immune responses in LcrV DNA vaccine induced protection against lethal $Y$. pestis challenge. Vaccine (2011) 29:6802-9. doi:10.1016/j.vaccine.2010.12.062

72. Wang S, Joshi S, Mboudjeka I, Liu F, Ling T, Goguen JD, et al. Relative immunogenicity and protection potential of candidate $Y$. pestis antigens against lethal mucosal plague challenge in Balb/C mice. Vaccine (2008) 26:1664-74. doi:10.1016/j.vaccine.2008.01.024

73. Chiuchiolo MJ, Boyer JL, Krause A, Senina S, Hackett NR, Crystal RG. Protective immunity against respiratory tract challenge with Yersinia pestis in mice immunized with an adenovirus-based vaccine vector expressing V antigen. J Infect Dis (2006) 194:1249-57. doi:10.1086/507644

74. Boyer JL, Sofer-Podesta C, Ang J, Hackett NR, Chiuchiolo MJ, Senina S, et al. Protective immunity against a lethal respiratory Yersinia pestis challenge induced by $\mathrm{V}$ antigen or the F1 capsular antigen incorporated into adenovirus capsid. Hum Gene Ther (2010) 21:891-901. doi:10.1089/hum. 2009.148

75. Sha J, Kirtley ML, Klages C, Erova TE, Telepnev M, Ponnusamy D, et al. A replication-defective human type 5 adenovirus-based trivalent vaccine confers complete protection against plague in mice and nonhuman primates. Clin Vaccine Immunol (2016) 7:586-600. doi:10.1128/CVI.00150-16 
76. Palin A, Chattopadhyay A, Park S, Delmas G, Suresh R, Senina S, et al. An optimized vaccine vector based on recombinant vesicular stomatitis virus gives high-level, long-term protection against Yersinia pestis challenge. Vaccine (2007) 25:741-50. doi:10.1016/j.vaccine.2006.08.010

77. Chattopadhyay A, Park S, Delmas G, Suresh R, Senina S, Perlin DS, et al. Single-dose, virus-vectored vaccine protection against Yersinia pestis challenge: CD4+ cells are required at the time of challenge for optimal protection. Vaccine (2008) 26:6329-37. doi:10.1016/j.vaccine.2008.09.031

78. Brewooa JN, Powell TD, Stinchcomb DT, Osorio JE. Efficacy and safety of a modified vaccinia Ankara (MVA) vectored plague vaccine in mice. Vaccine (2010) 28:5891-9. doi:10.1016/j.vaccine.2010.06.054

79. Bhattacharya D, Mecsas J, Hu LT. Development of a vaccinia virus based reservoir-targeted vaccine against Yersinia pestis. Vaccine (2010) 28:7683-9. doi:10.1016/j.vaccine.2010.09.039

80. Barton ES, White DW, Cathelyn JS, Brett-McClellan KA, Engle M, Diamond MS, et al. Herpesvirus latency confers symbiotic protection from bacterial infection. Nature (2007) 447:326-9. doi:10.1038/nature05762

81. Rocke TE, Pussini N, Smith SR, Williamson J, Powell B, Osorio JE. Consumption of baits containing raccoon pox-based plague vaccines protects black-tailed prairie dogs (Cynomys ludovicianus). Vector Borne Zoonotic Dis (2010) 1:53-8. doi:10.1089/vbz.2009.0050

82. Rocke TE, Kingstad-Bakke B, Berlier W, Osorio JE. A recombinant raccoon poxvirus vaccine expressing both Yersinia pestis F1 and truncated V antigens protects animals against lethal plague. Vaccines (Basel) (2014) 4:772-84. doi:10.3390/vaccines2040772

83. Tripp DW, Rocke TE, Streich SP, Abbott RC, Osorio JE, Miller MW. Apparent field safety of a raccoon poxvirus-vectored plague vaccine in free-ranging prairie dogs (Cynomys spp.), Colorado, USA. J Wildl Dis (2015) 2:401-10. doi:10.7589/2014-02-051

84. Leary SE, Griffin KF, Garmory HS, Williamson ED, Titball RW. Expression of an F1/V fusion protein in attenuated Salmonella typhimurium and protection of mice against plague. Microb Pathog (1997) 23:167-79. doi:10.1006/ mpat.1997.0141

85. Garmory HS, Griffin KF, Brown KA, Titball RW. Oral immunisation with live aroA attenuated Salmonella enterica serovar Typhimurium expressing the Yersinia pestis V antigen protects mice against plague. Vaccine (2003) 21:3051-7. doi:10.1016/S0264-410X(03)00112-9

86. Titball RW, Howells AM, Oyston PC, Williamson ED. Expression of the Yersinia pestis capsular antigen (F1 antigen) on the surface of an aroA mutant of Salmonella typhimurium induces high levels of protection against plague. Infect Immun (1997) 65:1926-30.

87. Yang X, Hinnebusch BJ, Trunkle T, Bosio CM, Suo Z, Tighe M, et al. Oral vaccination with Salmonella simultaneously expressing Yersinia pestis F1 and $\mathrm{V}$ antigens protects against bubonic and pneumonic plague. J Immunol (2007) 178:1059-67. doi:10.4049/jimmunol.178.2.1059

88. Morton M, Garmory HS, Perkins SD, O’Dowd AM, Griffin KF, Turner AK, et al. Salmonella enterica serovar Typhi vaccine expressing Yersinia pestis F1 antigen on its surface provides protection against plague in mice. Vaccine (2004) 22:2524-32. doi:10.1016/j.vaccine.2004.01.007

89. Ramirez K, Capozzo AV, Lloyd SA, Sztein MB, Nataro JP, Pasetti MF. Mucosally delivered Salmonella Typhi expressing the Yersinia pestis F1 antigen elicits mucosal and systemic immunity early in life and primes the neonatal immune system for a vigorous anamnestic response to parenteral F1 boost. J Immunol (2009) 182:1211-22. doi:10.4049/jimmunol.182.2.1211

90. Torres-Escobar A, Juarez-Rodriguez MD, Gunn BM, Branger CG, Tinge SA, Curtiss R III. Fine-tuning synthesis of Yersinia pestis LcrV from runaway-like replication balanced-lethal plasmid in a Salmonella enterica serovar typhimurium vaccine induces protection against a lethal $Y$. pestis challenge in mice. Infect Immun (2010) 78:2529-43. doi:10.1128/IAI.00005-10

91. Sun W, Roland KL, Curtiss R III. Developing live vaccines against plague. J Infect Dev Ctries (2011) 5:614-27. doi:10.3855/jidc.2030

92. Feodorova VA, Motin VL. Plague vaccines: current developments and future perspectives. Emerg Microbes Infect (2012) 1:e36. doi:10.1038/emi.2012.34

93. Daniel C, Sebbane F, Poiret S, Goudercourt D, Dewulf J, Mullet C, et al. Protection against Yersinia pseudotuberculosis infection conferred by a Lactococcus lactis mucosal delivery vector secreting LcrV. Vaccine (2009) 27:1141-4. doi:10.1016/j.vaccine.2008.12.022

94. Daniel C, Titecat M, Poiret S, Cayet D, Boutillier D, Simonet M, et al. Characterization of the protective immune response to Yersinia pseudotuberculosis infection in mice vaccinated with an LcrV-secreting strain of Lactococcus lactis. Vaccine (2016) 47:5762-7. doi:10.1016/j. vaccine.2016.09.060

95. Blisnick T, Ave P, Huerre M, Carniel E, Demeure CE. Oral vaccination against bubonic plague using a live avirulent Yersinia pseudotuberculosis strain. Infect Immun (2008) 8:3808-16. doi:10.1128/IAI.00034-08

96. Derbise A, Cerdà Marín A, Ave P, Blisnick T, Huerre M, Carniel E, et al. An encapsulated Yersinia pseudotuberculosis is a highly efficient vaccine against pneumonic plague. PLoS Negl Trop Dis (2012) 2:e1528. doi:10.1371/journal. pntd.0001528

97. Derbise A, Hanada Y, Khalifé M, Carniel E, Demeure CE. Complete protection against pneumonic and bubonic plague after a single oral vaccination. PLoS Negl Trop Dis (2015) 10:e0004162. doi:10.1371/journal.pntd.0004162

98. Demeure CE, Derbise A, Carniel E. Oral vaccination against plague using Yersinia pseudotuberculosis. Chem Biol Interact (2016). doi:10.1016/j. cbi.2016.03.030

99. Saltykova RA, Faibich MM. Experience from a 30-year study of the stability of the properties of the plague vaccine strain EV in the USSR. Zh Mikrobiol Epidemiol Immunobiol (1975) 6:3-8.

100. Feodorova VA, Pan'kina LN, Savostina EP, Sayapina LV, Motin VL, Dentovskaya SV, et al. Yersinia pestis lpxM-mutant live vaccine induces enhanced immunity against bubonic plague in mice and guinea pigs. Vaccine (2007) 25:7620-8. doi:10.1016/j.vaccine.2007.08.055

101. Feodorova VA, Pan'kina LN, Savostina EP, Kuznetsov OS, Konnov NP, Sayapina LV, et al. Pleiotropic effects of the lpxM mutation in Yersinia pestis resulting in modification of the biosynthesis of major immunoreactive antigens. Vaccine (2009) 27:2240-50. doi:10.1016/j.vaccine.2009.02.020

102. Poltorak A, Ricciardi-Castagnoli P, Citterio S, Beutler B. Physical contact between lipopolysaccharide and toll-like receptor 4 revealed by genetic complementation. Proc Natl Acad Sci U S A (2000) 97:2163-7. doi:10.1073/ pnas.040565397

103. Poltorak A, He X, Smirnova I, Liu MY, Van Huffel C, Du X, et al. Defective LPS signaling in $\mathrm{C} 3 \mathrm{H} / \mathrm{HeJ}$ and $\mathrm{C} 57 \mathrm{BL} / 10 \mathrm{ScCr}$ mice: mutations in TLR4 gene. Science (1998) 282:2085-8. doi:10.1126/science.282.5396.2085

104. Hoshino K, Takeuchi O, Kawai T, Sanjo H, Ogawa T, Takeda Y, et al. Cutting edge: toll-like receptor 4 (TLR4)-deficient mice are hyporesponsive to lipopolysaccharide: evidence for TLR4 as the Lps gene product. J Immunol (1999) 162:3749-52.

105. Lien E, Means TK, Heine H, Yoshimura A, Kusumoto S, Fukase K, et al. Toll-like receptor 4 imparts ligand-specific recognition of bacterial lipopolysaccharide. J Clin Invest (2000) 105:497-504. doi:10.1172/JCI8541

106. Montminy SW, Khan N, McGrath S, Walkowicz MJ, Sharp F, Conlon JE, et al. Virulence factors of Yersinia pestis are overcome by a strong lipopolysaccharide response. Nat Immunol (2006) 7:1066-73. doi:10.1038/ ni1386

107. Sha J, Agar SL, Baze WB, Olano JP, Fadl AA, Erova TE, et al. Braun lipoprotein (Lpp) contributes to virulence of yersiniae: potential role of Lpp in inducing bubonic and pneumonic plague. Infect Immun (2008) 76:1390-409. doi:10.1128/IAI.01529-07

108. Tidhar A, Flashner Y, Cohen S, Levi Y, Zauberman A, Gur D, et al. The NlpD lipoprotein is a novel Yersinia pestis virulence factor essential for the development of plague. PLoS One (2009) 4:e7023. doi:10.1371/journal.pone. 0007023

109. Cathelyn JS, Crosby SD, Lathem WW, Goldman WE, Miller VL. RovA, a global regulator of Yersinia pestis, specifically required for bubonic plague. Proc Natl Acad Sci U S A (2006) 103:13514-9. doi:10.1073/pnas.0603456103

110. Lu S. Two is better than one. Lancet Infect Dis (2011) 11:889-91. doi:10.1016/ s1473-3099(11)70256-0

Conflict of Interest Statement: The authors declare that the research was conducted in the absence of any commercial or financial relationships that could be construed as a potential conflict of interest.

Copyright (c) 2016 Verma and Tuteja. This is an open-access article distributed under the terms of the Creative Commons Attribution License (CC BY). The use, distribution or reproduction in other forums is permitted, provided the original author(s) or licensor are credited and that the original publication in this journal is cited, in accordance with accepted academic practice. No use, distribution or reproduction is permitted which does not comply with these terms. 